\title{
AUTO DOCUMENTATION TO HOSPITAL INFORMATION SYSTEM USING “BAR-CODED MEDICATION ADMINISTRATION"
}

\author{
MOHIT JAIN, SHOLA USHA RANI \\ Department of SCSE, Vellore Institute of Technology, Chennai, Tamil Nadu, India. Email: \\ vijayalakshmi.av@vit.ac.in
}

Received: 23 January 2017, Revised and Accepted: 03 March 2017

\section{ABSTRACT}

This paper is mainly on patient safety in health-care information technology (HIT). One of the main concerns with respect to this is recording all patient related information. One of the issues is auto documentation in HIT. Due to this, many medical errors are occurring, to avoid this automation to the patient history need to be supported. The patient will be linked with history, prescription, doctors, and nurse's information. All this information should be linked with one patient ID known as bar code. The outcome of care transformations of the medication administration process that resulted from the implementation of one type of IT: Bar-coded medication administration (BCMA). Hence, this paper shows the technologies of BCMA how it works and the drawback of it and the implementation on open-source platform of BCMA.

Keywords: Bar code, Radio-frequency identification, Medication management, Medical error, Near field communication

(C) 2017 The Authors. Published by Innovare Academic Sciences Pvt Ltd. This is an open access article under the CC BY license (http://creativecommons. org/licenses/by/4. 0/) DOI: http://dx.doi.org/10.22159/ajpcr.2017.v10s1.124

\section{INTRODUCTION}

Auto documentation to the health-care information technology all the information of the patient is maintained through traditional administration process like entering all the details of patient manually. Due to this, many medical errors are occurring to avoid this automation to the patient history need to be supported. The patient will be linked with history, prescription, doctors, and nurse's information. All this information should be linked with one patient ID known as a bar code. Moreover, the bar code scanner is used to retrieve the information about a patient.

It will reduce the nursing time and improve the drugs administration. Moreover, the physician can check the parameters by checking his ID. By this, the accuracy, usefulness, and consistency to check the patient have been improved. Bar-coded medication administration (BCMA) could save their oral drug administration time. BCMA could enhance patient oral medication safety and promote the quality of oral medication.

A bar code management system is consisted all the canners things such as a bar code printer, bar code scanner, bar-coded reader, computer server, and software. All the medication things are labelled with a unique bar code. The main role of bar code in medication is when a patient prescribes medications, they will be faxed and electronically delivered or manually delivered to a hospital pharmacy, where the nurse enters the computer system. The nurse will attach a bracelet to the patient. On that wristband, a unique bar code will be there. When a patient is used by a clinician to manage medication, the nurse will use a handheld device to scan his identification badge, the patient's wristband, and the bar code on the drug. It is also possible that the bar code cannot match because it is the unique ID provided to the patient, which will warn the nurse with a visual warning as each patient bar code holds all information about the patient and the medications provided.

There are five rights to be followed in bar code drug administration, namely, correct patient, correct medication, all correct time, all correct doses, and all correct routes. Through this thing, it will reduce medication errors.

\section{LITERATURE SURVEY}

\section{Structure of BCMA system}

BCMA's actual structure is basically divided into five parts, including the frame settings, login operation area, symbol record search, print log record structure, and frame crash reenters the segment. The frame setup has approval control, the head culture has the ability to change as indicated by the mass of each unit, and in addition, it can check the status of mediators that mediate medications and log on at the correct time later. The labelling procedure includes the choice of the patient's fracture; the ability to enter the case marker after checking the patient's wristband standard label, including this timeline, as well as intravenous (IV), details, PRN medications; each patient's solution can be identified by looking for markers record found. Thus, the BCMA system is used only for oral drug administration.

\section{RELATED WORK}

BCMA works with many different terminology and different technology also in this literature survey; we will discuss many types of terminology and how it will work in natural word.

\section{METHODS}

Medication management system (MMS)

In MMS, for the patient, it involves the following four stages:

- Ordering

- Transcribing

- Dispensing

- Administration.

The five or more "rights" of medication administration such as a right patient, right medication, right dose, right route, and right time have been identified and put in practice in many hospitals. This approach is very useful for reducing preventable medication errors. However, as they depend on the humans involved, it is difficult to guarantee them perfectly. Hence, the wireless bar code terminal used in the dispensing and administration of medication is to identify a patient and a medication.

In this figure, the process of medication for the patient by the help of bar codes is described. A nurse inputs a medicine order by the help of MMS. This order is clinically screened by a pharmacist as shown in Fig. 1. Then, the pharmacist nurse put the medicines that she has got by MMS in the smart drawer. A nurse picks up the correct medication from a smart drawer according to a medication list by reading a bar code. After dispensing but before administrating a medication, the nurse identifies the patient by reading the bar code on his or her bracelet. 
The benefit of this process is to increase the workload of nurse's. However, according to this terminology, $34 \%$ of medication error occurs during this administration process. Hence, to solve this, we propose using touch tag that uses a body area communication system instead of a bar code [1].

\section{Body area communication system}

In this process, a MMS is combining the both bar code and the touch tag. Research had designed the MMS for IV drip injection.

The MMS comprises the following units:

- Core MMS

- PC with a bar code reader

- Touch tag

- Touch tag access point.

It is a list of five or more "rights" of medication administration. It arranges to use the bit tag for creating links between the patient, nurse, and blood vessel bag throughout the administration of the medication. Once a nurse injects liquid medication into the blood vessel bag per the order list, she or he attaches slightly tag and a bar code label written out from the core MMS and reads the bit tag and also the bar code to link the bit tag to the blood vessel bag. Throughout the administration of medication, the nurse carries slightly tag reader and a list for 5 or a lot of "rights" of medication administration. The bit tag was hooked up to many points on the patient. The bit tag reader was assailed the waist, right lower arm, and right higher arm of members of our analysis teams rather than a nurse. The quantity of subjects was 2 during this case, and that we measured whether or not it had been potential to scan the ID of the bit tag 5 times for every position. Once the bit tag was on the lower or higher arm, the bit tag reader may continuously read the ID. We expect that the higher arm is a lot of appropriate than the lower arm, and as a result of it, it is a stronger place to avoid associate surprising bit.

\section{Places to put touch tag on IV bag}

We measured 5 times whether it was possible to read the ID on the touch tag on a pet bottle instead of an IV bag. We measured the bottle filled with water and the bottle empty. When the bottle was filled with water, the ID was readable regardless of where the tag was on the bottle. However, when a bottle was empty, it was impossible to reliably read the ID [1]. We evaluated the following direct touch and indirect touch situations as follows:

\section{Direct touch}

The topic holds a bag together (with his|along with his) or her arm while not a tag reader on that and touches the tag directly with his or her arm with the tag reader on that.

\section{Indirect touch}

The topic holds a bag mistreatment his or her arm while not slightly tag reader on that and touches some portion of a bag except the tag itself by mistreatment the arm on that the tag reader is about. We measured the received signal level in the following four cases:

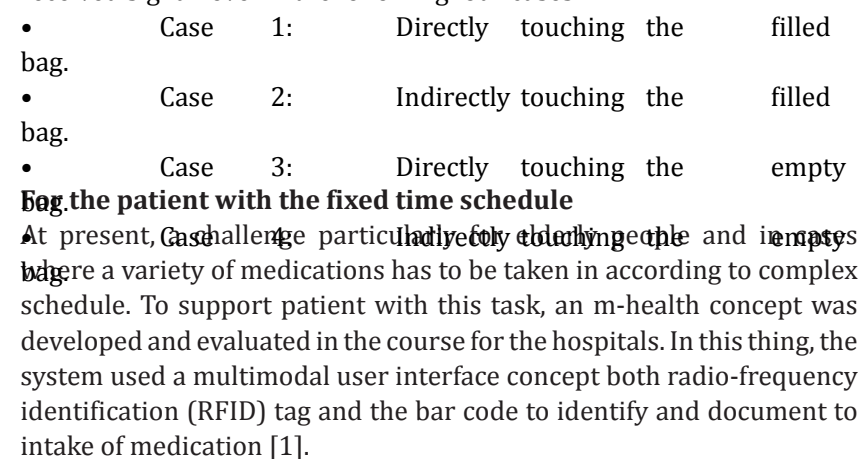

Near field communication (NFC) is an increasingly available wireless interface in current and future mobile phones and smartphones. It is a short-range $(<10 \mathrm{~cm})$ wireless technology for RFID that can be read and written using the NFC features of smartphones, particularly with publicly available NFC development applications. The aim of NFC is to read RFID tags and the mobile phone camera to scan the bar code.

\section{Medication management (RFID)}

It started by touching the medication box with the NFC enable in a smartphone. When RFID tag was read out for the first time, an additional question had to be defined by the patient after scanning the bar code. This additional question was then asked each time after the documentation of that specific drug.

Then, the documentation was stored in a SQL database on the smartphone. The architecture of the database consisted of tables for the drug, the prescribed schedule, the linkage between unique ID stored on the RFID tag and the drug, and the table to keep track of the adherence, i.e., store the data on the intake as documented by the patient (Fig. 2).

After saving the information, an unique ID stored on the RFID tag and it will create a specific time slot [2]. After documentation of the intake, drug disappeared from that list, and it will display all the medication taken in the actual day. If the documentation was not taken or done within the time slot, a reminder dialog will appear and the warning was issued.

\section{RFID and the bar code used in pregnancy}

This exploration shows a RFID application in OGD prompted to diminishment of the staff in stock office which diminishes the cost of work. The advantages of RFID in bar-coded framework are that the attendant in the clinic can track resources quick.

- This can expand the quality and effectiveness of the doctor's facility.

- And can keep away from burglary and theft by characterizing are of gear.

RFID system is collected for three different periods as follows:

1. Pregnancy

2. Delivery

3. After childbirth.

The saving time for each period is obtained based on the waiting time difference between two systems, where the saving time is converted

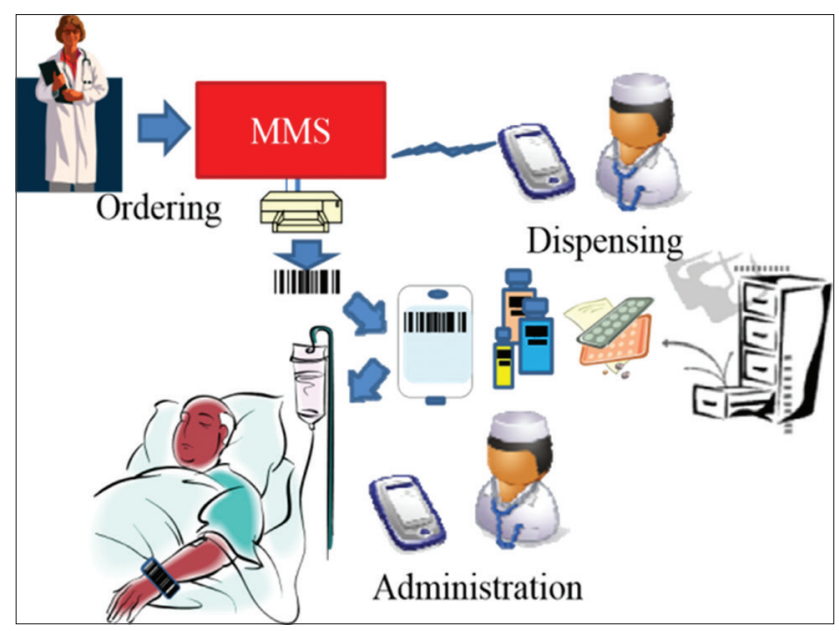

Fig. 1: System configuration of the medication management system with the bar code [1]

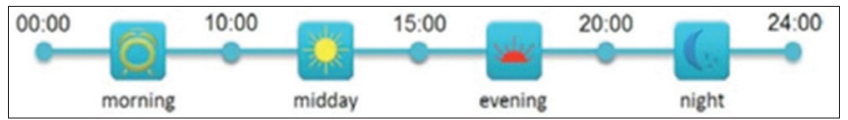

Fig. 2: Define time slot for each time of day category [2] 
to money. In this terminology, the woman will get a card that is RFID smart card. The cost of the smart card will paid, and it will utilized by a pregnant patient for the motivation behind information recording and scheduling amid patient visit to OGD Office. This card holds all the historical backdrop of patient from the $1^{\text {st }}$ day of pregnancy up to the most recent month after labor. In this, every period comprises of various number of visits and exercises. All visits required stride for every period.

The advantage of this module is as follows:

- Time saving for doctor, nurses, administrator, and patient.

- They can convert time into money.

- To increase the quality and efficiency of the hospital [4].

\section{DOCTOR CARD}

The bar code representation is printed on the card as a physician card number. The bar code is used to make a task of the hospital easier, and every detail of the physician will contain the bar code. The bar code system for each physician and nurse will have a bar code printed on the card. Bar code technology has been used in this system. It has a low cost, is easy to use, and does not require an incredibly differentiated proof process because the bar code will represent the information directly. RFID technology has been proposed for use in this participant system; however, it is not comfortable because the chip installed in the physician's card represents a number in the card itself, not the doctor's ID number. This will cause inconvenience to the system when creating a database for participation lists. The participation list will be based on the doctor and ID number, and the comparison process within the name list will be inconsistent. If the system has a general list of RFIDs, RFID technology can be used a novel number of the doctor's card which can be represented as the doctor's ID number accordingly.

As we tend to see during this Fig. 3, the cardboard contains each detail with the bar code. The factor is once the doctor offers that attending the sole work is to try and do they need to scan the bar code and also the attending can mechanically store knowledge he info the information base of hospital this nomenclature used for the doctor's time saving, and it maintains all the main points of doctor's details in data base.

There are 2 places to gather: Log in and consider. Once the participation list is set into the dataset, the login and checkout methods may be difficult to observe. Fig. 4 shows the Windows kind style once logged in or consider the method being run. In this window type, there is a text box and a button labelled "Commit." Throughout the development method, the maximum number of text boxes has been set to 15 . The text box input can be a manual input with a keyboard. However, to form a recording method flow, a bar code scanner must be forced. Since the bar code scanner decodes the bar code from the physician card, the 10-digit ID type is similar to the text box using the HID keyboard emulation technique. It displays the ID variable in the text box [7].

\section{PROPOSED WORK}

We will discuss about the existing work drawback by the first module that a nurse has to carry a handy terminal that includes a bar code reader function and put it over the patient's bracelet. This action increases the nurse's workload and must be stressful for a nurse at the bedside. These issues mean that a bar code is not the most suitable for use at the bedside. Moreover, in NFC and RFID, patients evaluated the usability of the proposed MMS using NFC-enabled smartphones and RFID tags as well as the phone's camera to scan bar codes. It is not possible for all the patients that they all have the smartphone. In pregnancy module, the problem is the smart card tag that cost is very high and it is not easy to every patient to purchase that card and the medication cost is also so costly, so this is a big drawback of this module (Fig. 5).

Hence, we will implement on open-source software that works on bar code. The advantage of this implement is that all the detail, medication detail, and all the clinical detail will be stored in this software database.

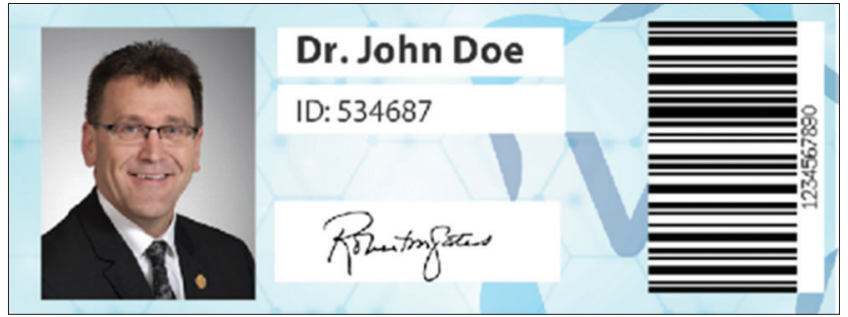

Fig. 3: Doctor ID card with the bar code [7]

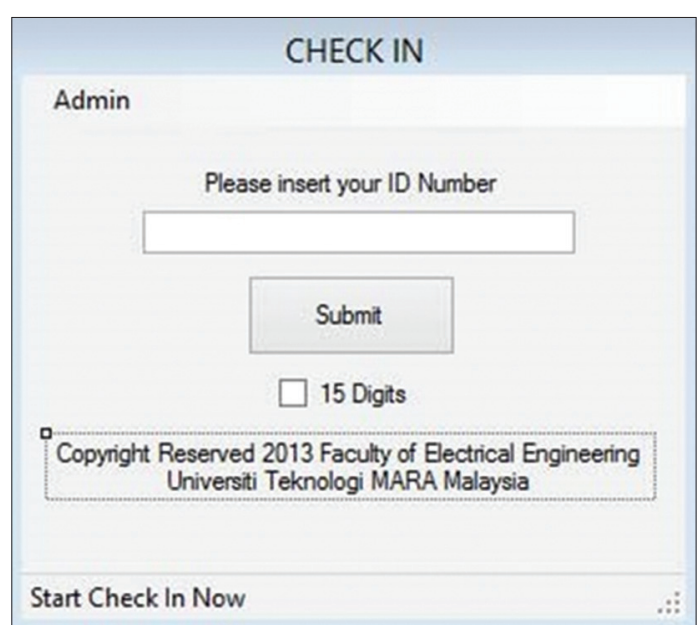

Fig. 4: Windows display for check in-out process [7]

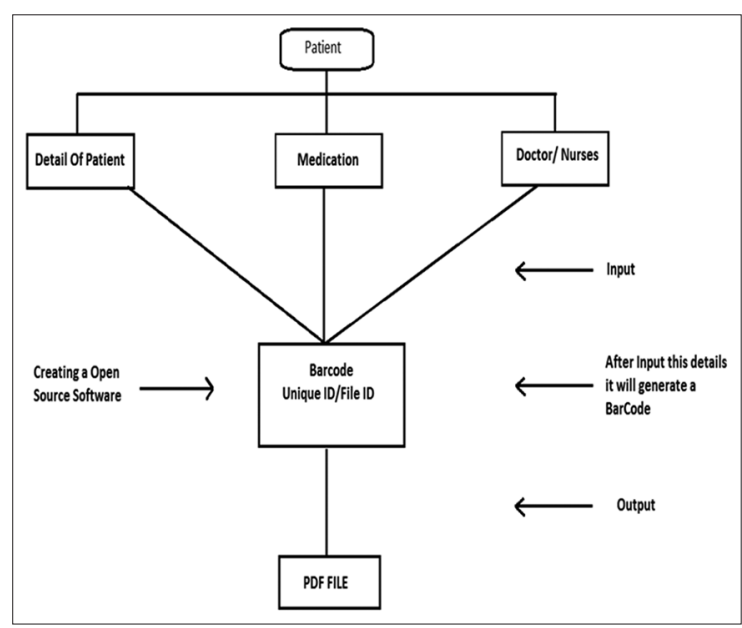

Fig. 5: Patient data integration process

It will create unique bar code tag for the entire patient. The biggest advantage is when we will scan that bar code all the details of the patient detail will come on screen, and thereafter, the software will generate a PDF file as an output. This will secure the details of patient and it will save more time for the hospital.

\section{CONCLUSION}

The paper explains the implementation of BCMA and RFID to reduce half of the time giving the oral medication. By the help of this, all the nurses have saved their $50 \%$ of the time. Nurses will work with the hardware and software with the new facilities and terminology of BCMA system.

The RFID application in OGD prompted to diminishment of the representatives in stock office that abatements the estimation of 
work. Inside the new framework abuse RFID, the degree of stock is controlled simpler and in extra better than average means than code framework. Revision is put mechanically and cut back the esteem inside the method for stock outs and losing customer. Legitimacy of drugs is controlled by RFID framework which winds up in less medicine mistake in consideration framework. Associate in nursing experiment demonstrating that the bit tag was helpful for very factory the link between an endogenous bag, a patient, and a nurse. Our system would not increase the employment or stress of a nurse and that we believe it will facilitate eliminate most of the preventable medication errors.

\section{REFERENCES}

1. Murata Y, Ikuta S, Sato N, Takayama T. Medication error protection system with a body area communication tag. In: Proceeding of ITU Kaleidoscope: Building Sustainable Communities (K-2013). ???: IEEE; 2013. p. 1-7.

2. Latré B, Braem B, Moerman I, Blondia C, Demeester P. A survey on wireless body area networks. Wirel Netw 2011;17(1):1-18.

3. Kado Y. RedTacton near-body electric-field communications technology and its applications. NTT Tech Rev 2010;8(3):1-6.

4. Blasinski H, Bulan O, Sharma G. Per-colorant-channel color barcodes for mobile applications: An interference cancellation frame work. IEEE Trans Image Process 2013;22(4):498-1511.

5. Al-Kattan I, Anjamrooz T. The Financial Impact of Using RFID in Healthcare. In: Industrial Engineering and Engineering Management (IEEM). IEEE International Conference; 2012. p. 1820-4

6. Holden RJ, Brown RL, Alper SJ, Scanlon MC, Patel NR, Karsh BT. That's nice, but what does IT do? Evaluating the impact of bar coded medication administration by measuring changes in the process of care. Int J Ind Ergon 2012;41(4):370-9.

7. Sulaiman AA, Bakar MA, Noor MZ, Abdullah SA. Easy Access Attendance Management System (EAMS). In: Engineering Education (ICEED). IEEE $6^{\text {th }}$ Conference on IEEE; 2014. p. 105-10.

8. Galiyawala HJ, Pandya KH. To Increase Data Capacity of QR Code Using Multiplexing With Color Coding: An Example of Embedding Speech Signal in QR Code. In: India Conference (INDICON), Annual IEEE; 2014. p. 1-6.
9. Huang HC, Chang FC, Fang WC. Reversible data hiding with histogram-based difference expansion for QR code applications. IEEE Trans Consum Electron 2011;57(2):779-87.

10. Huang HC, Fang WC, Tsai IT. Reversible Data Hiding Using HistogramBased Difference Expansion. In: Circuits and Systems, ISCAS; 2009. IEEE International Symposium on IEEE; 2009. p. 1661-4.

11. Sadikin MA, Sunaringtyas SU. Implementing Digital Signature for the Secure Electronic Prescription Using QR-Code Based on Android Smartphone. In: Technology of Information and Communication (ISemantic). International Seminar on Application for IEEE; 2016. p. 306-11.

12. Umaria MM, Jethava GB. Enhancing the Data Storage Capacity in QR Code Using Compression Algorithm and Achieving Security and Further Data Storage Capacity Improvement Using Multiplexing. In: Computational Intelligence and Communication Networks (CICN). International Conference on IEEE; 2015. p. 1094-6.

13. Chen B, Qiang XH, Yu L. A Lightweight Color Barcode Algorithm and Application in Mobile E-Commerce. In: Computer Science and Education (ICCSE). $8^{\text {th }}$ International Conference on IEEE; 2013. p. 805-9.

14. Sulaiman AA, Bakar MA, Noor MZ, Abdullah SA. Easy Access Attendance Management System (EAMS). In: Engineering Education (ICEED). IEEE $6^{\text {th }}$ Conference on IEEE; 2014. p. 105-10.

15. Ampt A, Westbrook JI. Measuring nurses' time in medication related tasks prior to the implementation of an electronic medication management system. Stud Health Technol Inform 2007;130:157.

16. Keohane CA, Bane AD, Featherstone E, Hayes J, Woolf S, Hurley A, et al. Quantifying nursing workflow in medication administration. J Nurs Adm 2008;38(1):19-26.

17. Coyle GA, Heinen M. Evolution of BCMA within the department of veteran's affairs. Nurs Adm Q 2005;29(1):32-8.

18. Paoletti RD, Suess TM, Lesko MG, Feroli AA, Kennel JA, Mahler JM, et al. Using bar-code technology and medication observation methodology for safer medication administration. Am J Health Syst Pharm 2007;64(5):536-43.

19. Gao JZ, Shim S, Mei H, Su X. Engineering Wireless-Based Software Systems and Applications. USA: Artech House, INC; 2006.

20. Xie YZ, Liu YH. Design of Internet Online Payment System Bases on QR Barcode. Wuhan: Hubei University of Technology; 2011. 